\title{
Breast conserving therapy for central breast cancer in the United States
}

\author{
Jiameng Liu' ${ }^{1,2 \dagger}$, Xiaobin Zheng ${ }^{1,5 \dagger}$, Shunguo Lin ${ }^{2,3,4}$, Hui Han ${ }^{2,3,4}$ and Chunsen $X^{2,3,4^{*}}$
}

\begin{abstract}
Introduction: Although central breast cancer is not a contraindication to breast conserving, most surgeons still choose to perform total mastectomy. The safety of breast conserving treatment for central breast cancer is still unclear. The purpose of this study is to evaluate the long-term survival outcome of central breast cancer.

Materials and methods: Using SEER database to explore the trend of surgical procedures for patients with central breast cancer. The patients were divided into breast conserving group and non-breast conserving group. Multivariate logistic regression was used to evaluate predictors of breast conserving surgery in central breast cancer. The clinicopathological variables were adjusted through the multivariable Cox risk model, and the stage and T stage were stratified to compare survival results.

Results: A total of 8702 patients with central breast cancer underwent surgical treatment from 2010 to 2015. There were 3870 patients in the breast conserving group and 4832 patients in the non-breast conserving group. The breast preservation rate was 44.4\%, which rose from 39.9\% in 2010 to 51\% in 2015. Elderly patients $(p<0.001)$ and low tumor malignancy were predictors of breast conserving therapy. In the 1:1 matched case-control analysis, breast cancerspecific survival (BCSS) $(p<0.001)$ and overall survival (OS) $(p<0.001)$ in breast conserving therapy group were still higher than those of non-breast conserving. In the subgroup analysis of T staging and stage, the breast conserving therapy group still had higher OS and BCSS.
\end{abstract}

Conclusion: In central breast cancer, breast-conserving therapy is safe and optional.

Keywords: Central breast cancer, Nipple-areola complex, Breast conserving therapy, Overall survival, Breast cancerspecific survival

\section{Introduction}

Breast conserving therapy $(\mathrm{BCT})$ allows patients to achieve esthetic outcomes, quality of life and preserve their breast without sacrificing oncologic outcome [1$3]$ and is considered as a safe treatment for early-stage breast cancer.

*Correspondence: xuchunsen@yeah.net

${ }^{\dagger}$ Jiameng Liu and Xiaobin Zheng have contributed equally to this work and share first authorship

2 Department of Breast Surgery, Fujian Medical University Union Hospital,

No. 29, Xinquan Road, Fuzhou 350001, Fujian, China

Full list of author information is available at the end of the article
Central breast cancer usually refers to tumors located in the area within $2 \mathrm{~cm}$ of the nipple-areola complex (NAC). The research on BCT of central breast cancer were few and small sample size though the results showed acceptable recurrence rate of BCT in central breast cancer $(4.8-7 \%)$ [4-6] and the non-inferior survival outcomes $[5,7,8]$ compared with non-BCT. So for central cancers breast conserving therapy was not contraindication in the guideline, but was less likely to be recommended by surgeons for reasons below: (1) careful pathologic examination of mastectomy specimens has found that more than $30 \%$ involve the nipple-areola complex [9-11] and lumpectomies that remove the nipple-areola complex often result in poor cosmesis. (2) 
Perceived increase in the risk of local recurrence owing to inadequate margins. Recent stunning result was reported from a SEER data based research including 16522 central breast cancer which showed an improved survival rate for centrally located breast cancer (CLBC) receiving $B C T$ [12]. But the early studies on the safety of BCT for CLBC $[4,13-16]$ or the comparation of oncological outcomes between $\mathrm{BCT}$ and non-BCT $[7,8]$ and the recent SEER based result [12] were all constrained to T1-2 stage without taking T3-4 into account which cannot meet the increasing demand for more cosmetically acceptable breast cancer surgery. Also HER-2 status was an important factors influencing the survival outcome of breast cancer, which was not included in the recent SEER based result. So a study on the survival difference between $\mathrm{BCT}$ and non-BCT in central and NAC, especially in T3-4 subgroup population is urgently need.

\section{Materials and methods}

\section{Data source and study population}

The Surveillance, Epidemiology, and End Results (SEER) database was used to evaluate the safety of breast conserving therapy. We acquired permission to download and analyze data for academic purpose (reference number: 10727-Nov2020). This study does not contain any experiments on humans as well as animals and/or the use of human tissue samples performed by any of the authors. The SEER cancer registries provide populationbased cancer surveillance for 17 areas that represent approximately $26 \%$ of the United States. Inclusion criteria: (1) the diagnosing year ranged from 2010 to 2015, (2) the primary site of tumor was breast, (3) tumor site was central portion of breast (C50.1) or nipple (C50.0), and (4) patients underwent breast surgery. Exclusion criteria: (1) patients with stage IV disease, (2) patients with unknown information of race, diagnosing year, marital status or important clinicopathological data, (3) patients younger than 18 years old or elder than 80 , (4) patients with a history of other cancer, (5) patients with less than 1 month survival after diagnosis, and (6) patient's diagnoses were only depended on biopsy or autopsy. Finally, a total of 8702 adult breast cancer patients aged 19 to 79 years between 2010 and 2015 was included, and we stratified patients into 2 groups by type of surgery: breast conserving therapy $(n=3870)$ and non-breast conserving therapy $(\mathrm{n}=4832)$. The non-breast conserving therapy included mastectomy and breast reconstruction.

\section{Statistical analysis}

Chi-squared testing was used to compare the differences in baseline characteristics between patients treated with non-BCT versus patients treated with BCT. Multivariable logistic regression was used to identify factors associated with surgery type. Kaplan-Meier analysis was used to compare overall survival outcomes between patients treated with different surgery type. Univariate and Multivariate Cox regression analysis was used to assess potential factors affecting breast cancer-specific survival (BCSS) and overall survival (OS) in patients with central breast cancer. Factors evaluated in the multivariate analysis model included surgery type, age at diagnosis, race, marital status, year at diagnosis, grade, $\mathrm{T}$ stage, $\mathrm{N}$ stage, ER status, PR status, and HER-2 status. To diminish the effects of baseline differences on outcome differences in the $\mathrm{BCT}$ and non-BCT groups, the propensity score matching (PSM) method was applied by matching each $\mathrm{BCT}$ case to non-BCT cases. They were exactly matched for the age, race, marital status, grade, $\mathrm{T}$ stage, $\mathrm{N}$ stage, ER status, PR status and HER-2 status. $\mathrm{P}<0.05$ was considered as an indicator of statistical significance. SPSS statistics (version 22, IBM, NY) was used to conduct all the above analyses.

\section{Results}

The trend of $\mathrm{BCT}$ and non-BCT among central breast cancer and relevant clinical characteristics

From 2010 to 2015, a total of 8702 patients met our inclusion criteria and were included for analysis. The study consisted of 3870 (44.4\%) patients with BCT and 4832 (55.6\%) patients with non-BCT. The clinical characteristics of the $\mathrm{BCT}$ and non-BCT groups were summarized in Table 1. BCT was performed more frequently since 2010. Older patients, white patients, married patients, gradeII, early stage, T1 stage, N0 stage, ER positive, PR positive, HER-2 negative were more likely to receive BCT, and the proportion of those factors differed significantly between $\mathrm{BCT}$ and non-BCT group except for marital status. Comparing patients treated with non-BCT, patients initially treated with $\mathrm{BCT}$ were older at diagnosis $(\mathrm{P}<0.001)$, have lower grade $(\mathrm{P}<0.001)$, lower TNM stage $(\mathrm{P}<0.001)$, lower $\mathrm{T}$ stage $(\mathrm{P}<0.001)$, lower $\mathrm{N}$ stage $(\mathrm{P}<0.001)$ and more likely to be ER positive at diagnosis $(\mathrm{P}<0.001)$, $\mathrm{PR}$ positive at diagnosis $(\mathrm{P}<0.001)$ and HER-2 negative at diagnosis $(\mathrm{P}<0.001)$. They are also more likely to be of white race $(\mathrm{P}<0.001)$. Figure 1 showed a trend 
Table 1 Comparison of patient and tumor characteristics between the BCT and non-BCT group

\begin{tabular}{|c|c|c|c|c|c|}
\hline & \multicolumn{2}{|c|}{$\mathrm{BCT}$ group } & \multicolumn{2}{|c|}{ Non-BCT group } & \multirow[t]{2}{*}{$P$-value } \\
\hline & No & $\%$ & No & $\%$ & \\
\hline Years at diagnosis & & & & & $<0.001$ \\
\hline 2010 & 570 & 14.70 & 859 & 17.80 & \\
\hline 2011 & 598 & 15.50 & 745 & 15.40 & \\
\hline 2012 & 627 & 16.20 & 868 & 18.00 & \\
\hline 2013 & 619 & 16.00 & 836 & 17.30 & \\
\hline 2014 & 681 & 17.60 & 779 & 16.10 & \\
\hline 2015 & 775 & 20.00 & 745 & 15.40 & \\
\hline Age & & & & & $<0.001$ \\
\hline$<45$ & 249 & 6.40 & 717 & 14.80 & \\
\hline $45-59$ & 1331 & 34.40 & 1861 & 38.50 & \\
\hline 60-79 & 2290 & 59.20 & 2254 & 46.60 & \\
\hline Race & & & & & $<0.001$ \\
\hline White & 3165 & 81.80 & 3711 & 76.80 & \\
\hline Black & 349 & 9.00 & 474 & 9.80 & \\
\hline Others & 356 & 9.20 & 647 & 13.40 & \\
\hline Marital & & & & & 0.439 \\
\hline Married & 2370 & 61.20 & 2911 & 60.20 & \\
\hline Single & 577 & 14.90 & 767 & 15.90 & \\
\hline Divorced & 923 & 23.90 & 1154 & 23.90 & \\
\hline Grade & & & & & $<0.001$ \\
\hline Grade I & 1037 & 26.80 & 780 & 16.10 & \\
\hline Grade II & 1908 & 49.30 & 2343 & 48.50 & \\
\hline Grade III & 918 & 23.70 & 1692 & 35.00 & \\
\hline Grade IV & 7 & 0.20 & 17 & 0.40 & \\
\hline Stage & & & & & $<0.001$ \\
\hline Stage I & 2218 & 57.30 & 1311 & 27.10 & \\
\hline Stage II & 1439 & 37.20 & 2198 & 45.50 & \\
\hline Stage III & 213 & 5.50 & 1323 & 27.40 & \\
\hline T stage & & & & & $<0.001$ \\
\hline $\mathrm{T} 1$ & 2766 & 71.50 & 1924 & 39.80 & \\
\hline $\mathrm{T} 2$ & 971 & 25.10 & 1961 & 40.60 & \\
\hline T3 & 79 & 2.00 & 598 & 12.40 & \\
\hline $\mathrm{T} 4$ & 54 & 1.40 & 349 & 7.20 & \\
\hline N stage & & & & & $<0.001$ \\
\hline NO & 2810 & 72.60 & 2266 & 46.90 & \\
\hline N1 & 917 & 23.70 & 1687 & 34.90 & \\
\hline N2 & 107 & 2.80 & 560 & 11.60 & \\
\hline N3 & 36 & 0.90 & 319 & 6.60 & \\
\hline ER status & & & & & $<0.001$ \\
\hline Negative & 434 & 11.20 & 742 & 15.40 & \\
\hline Positive & 3436 & 88.80 & 4090 & 84.60 & \\
\hline PR status & & & & & $<0.001$ \\
\hline Negative & 800 & 20.70 & 1263 & 26.10 & \\
\hline Positive & 3070 & 79.30 & 3569 & 73.90 & \\
\hline HER-2 status & & & & & $<0.001$ \\
\hline Negative & 3350 & 86.60 & 3889 & 80.50 & \\
\hline Positive & 520 & 13.40 & 943 & 19.50 & \\
\hline
\end{tabular}

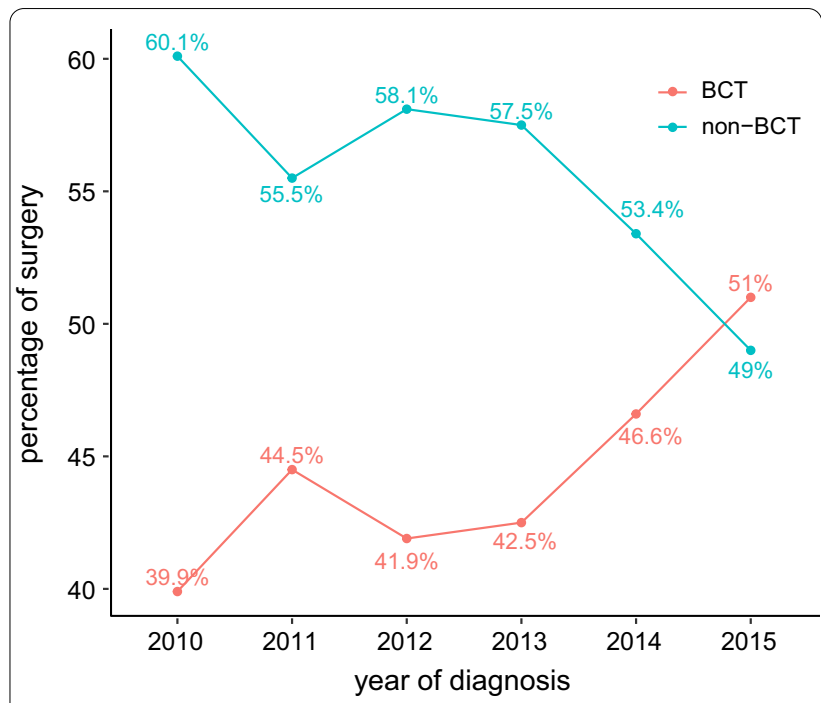

Fig. 1 Proportion of patients with central breast cancer who underwent $\mathrm{BCT}$ and those who underwent non-BCT diagnosed between 2010 and 2015

of $\mathrm{BCT}$ for T1-4 central breast cancer and the $\mathrm{BCT}$ rate (51\%) exceeded non-BCT in 2015.

\section{Predictive factors of $\mathrm{BCT}$ among central breast cancer}

The results of multivariate logistic regression are reported in Table 2. Results confirmed that higher $\mathrm{T}$ stage $(\mathrm{P}<0.001$; $\mathrm{T} 2$ : OR $0.447,95 \%$ CI $0.402-0.496$; $\mathrm{T} 3$ : OR 0.152 , 95\% CI $0.118-0.195$; T4: OR $0.182,95 \%$ CI $0.134-0.247)$, higher $\mathrm{N}$ stage $(\mathrm{P}<0.001$; N1: OR 0.634 , 95\%CI 0.570-0.706; N2: OR 0.304, 95\%CI 0.242-0.381; N3: OR 0.216, 95\%CI 0.150-0.311), positive HER-2 status $(\mathrm{P}=0.004$; OR0.822 95\%CI 0.719-0.940) and higher grade $(\mathrm{P}=0.014$; Grade II: OR $0.843,95 \% \mathrm{CI} 0.747-0.951$; Grade III: OR 0.819 , 95\%CI $0.707-0.949$ ) were independently associated with non-BCT. Other significant predictors of BCT include higher age (45-59 years: OR 2.026, 95\% CI 1.706-2.405; 60-79 years: OR 2.581, 95\% CI 2.182-3.053) and years at diagnosis (OR 1.076, 95\% CI 1.048-1.106).

\section{Survival significance of $\mathrm{BCT}$ among central breast cancer}

The Kaplan-Meier survival curve showed that BCT group had better OS and BCSS than non-BCT group (Fig. 2, both $\mathrm{P}<0.001$ ). For patients with central breast cancer, type of surgery, age, race, marital status, years at diagnosis, grade, $\mathrm{T}$ stage, $\mathrm{N}$ stage, ER status, $\mathrm{PR}$ status and HER-2 status were considered as potential prognostic variables and were included in the initial univariate and multivariate models. The results of the univariate analysis proportional hazard regression 
Table 2 Multivariate logistic regressions model for predictors of breast conserving therapy

\begin{tabular}{|c|c|c|c|}
\hline Factor & OR & $95 \% \mathrm{Cl}$ & $P$-value \\
\hline Age & & & $<0.001$ \\
\hline$<45$ & 1 & Reference & \\
\hline $45-59$ & 2.026 & $1.706-2.405$ & $<0.001$ \\
\hline $60-79$ & 2.581 & $2.182-3.053$ & $<0.001$ \\
\hline Race & & & $<0.001$ \\
\hline White & 1 & Reference & \\
\hline Black & 1.030 & $0.874-1.213$ & 0.725 \\
\hline Others & 0.680 & $0.585-0.79$ & $<0.001$ \\
\hline Marital & & & 0.059 \\
\hline Married & 1 & Reference & \\
\hline Single & 1.146 & $1.001-1.313$ & 0.049 \\
\hline Divorced & 0.952 & $0.850-1.067$ & 0.4 \\
\hline Year of diagnosis & 1.076 & $1.048-1.106$ & $<0.001$ \\
\hline Grade & & & 0.014 \\
\hline Grade I & 1 & Reference & \\
\hline Grade II & 0.843 & $0.747-0.951$ & 0.005 \\
\hline Grade III & 0.819 & $0.707-0.949$ & 0.008 \\
\hline Grade IV & 0.477 & $0.182-1.251$ & 0.132 \\
\hline Tstage & & & $<0.001$ \\
\hline $\mathrm{T} 1$ & 1 & Reference & \\
\hline $\mathrm{T} 2$ & 0.447 & $0.402-0.496$ & $<0.001$ \\
\hline $\mathrm{T} 3$ & 0.152 & $0.118-0.195$ & $<0.001$ \\
\hline $\mathrm{T} 4$ & 0.182 & $0.134-0.247$ & $<0.001$ \\
\hline N stage & & & $<0.001$ \\
\hline NO & 1 & Reference & \\
\hline N1 & 0.634 & $0.57-0.706$ & $<0.001$ \\
\hline N2 & 0.304 & $0.242-0.381$ & $<0.001$ \\
\hline N3 & 0.216 & $0.150-0.311$ & $<0.001$ \\
\hline ER status & & & 0.987 \\
\hline Negative & 1 & Reference & \\
\hline Positive & 1.002 & $0.829-1.209$ & 0.987 \\
\hline PR status & & & 0.082 \\
\hline Negative & 1 & Reference & \\
\hline Positive & 1.141 & $0.984-1.323$ & 0.082 \\
\hline HER-2 status & & & 0.004 \\
\hline Negative & 1 & Reference & \\
\hline Positive & 0.822 & $0.719-0.94$ & 0.004 \\
\hline
\end{tabular}

identified BCT significantly reduced overall death hazard (HR 0.396; 95\%CT 0.332-0.473; $\mathrm{P}<0.001$ ) and breast-specific death hazard (HR 0.266; 95\%CT 0.2060.342 ; $\mathrm{P}<0.001$ ) (Tables 3,4 ). And BCT still significantly reduced overall death hazard (HR 0.633; 95\%CT
$0.522-0.766 ; \mathrm{P}<0.001)$ and breast-specific death hazard (HR 0.570; 95\%CT 0.435-0.746; $\mathrm{P}<0.001$ ) in the adjust multivariate Cox analysis. Other factors including age $(\mathrm{P}<0.001)$, race $(\mathrm{P}<0.001)$, marital status $(\mathrm{P}<0.001)$, years at diagnosis $(P=0.038)$, grade $(\mathrm{P}<0.001)$, T stage $(\mathrm{P}<0.001), \mathrm{N}$ stage $(\mathrm{P}<0.001)$, ER status $(\mathrm{P}=0.003)$, PR status $(\mathrm{P}<0.001)$ and HER-2 status $(\mathrm{P}=0.039)$ were identified as independent significant predictors of T1-4 central breast cancer overall mortality (OM), and race $(\mathrm{P}<0.001)$, marital status $(\mathrm{P}=0.007)$, grade $(\mathrm{P}<0.001)$, $\mathrm{T}$ stage $(\mathrm{P}<0.001), \mathrm{N}$ stage $(\mathrm{P}<0.001)$, ER status $(\mathrm{P}=0.005), \mathrm{PR}$ status $(\mathrm{P}<0.001)$ and HER-2 status $(\mathrm{P}=0.008)$ were identified as independent significant predictors of central breast cancer breast-specific mortality (BCSM).

\section{$\mathrm{BCT}$ as a prognostic factor for survival after propensity score matching}

To further corroborate the findings from univariable and multivariable proportional hazard regression, a propensity score-adjusted analysis was performed. A total of 2757 patients who underwent BCT were matched to 2757 patients who underwent non-BCT. Within the postpropensity cohort, there was no difference between both groups with regards to age $(\mathrm{P}=0.114)$, race $(\mathrm{P}=0.527)$, marital status $(\mathrm{P}=0.287)$, grade $(\mathrm{P}=0.669), \mathrm{T}$ stage $(\mathrm{P}=0.722), \mathrm{N}$ stage $(\mathrm{P}=0.547)$, ER status $(\mathrm{P}=0.579), \mathrm{PR}$ status $(\mathrm{P}=0.409)$ and HER-2 status $(\mathrm{P}=0.458)$ (Table 5$)$. Using Kaplan-Meier survival estimates, BCT was associated with improved OS $(\mathrm{P}=0.001)$ (Fig. 3$)$ in the postpropensity cohort. In the subgroup analysis based on the post-propensity cohort. The beneficial impact of BCT on survival was additionally confirmed stratified for stage, and the $\mathrm{P}$ value were 0.018 for stage $\mathrm{I}, 0.009$ for stage II, and 0.004 for stage III (Fig. 4). The BCT group had a higher OS compared with the non-BCT group in T1-2 $(\mathrm{P}<0.001)$ and $\mathrm{T} 3-4(\mathrm{P}=0.037)$ (Fig. 5).

\section{Discussion}

$\mathrm{BCT}$ involves excision of the tumor (lumpectomy) followed by adjuvant whole breast irradiation (WBI). In order to perform $\mathrm{BCT}$, it must be possible to excise the tumor to negative margins with an acceptable cosmetic outcome, the patient must be able to receive radiotherapy, and the breast must be suitable for follow-up to allow prompt detection of local recurrence. Landmark trials have established that breast conservation therapy (BCT) and mastectomy offer equivalent survival and can 

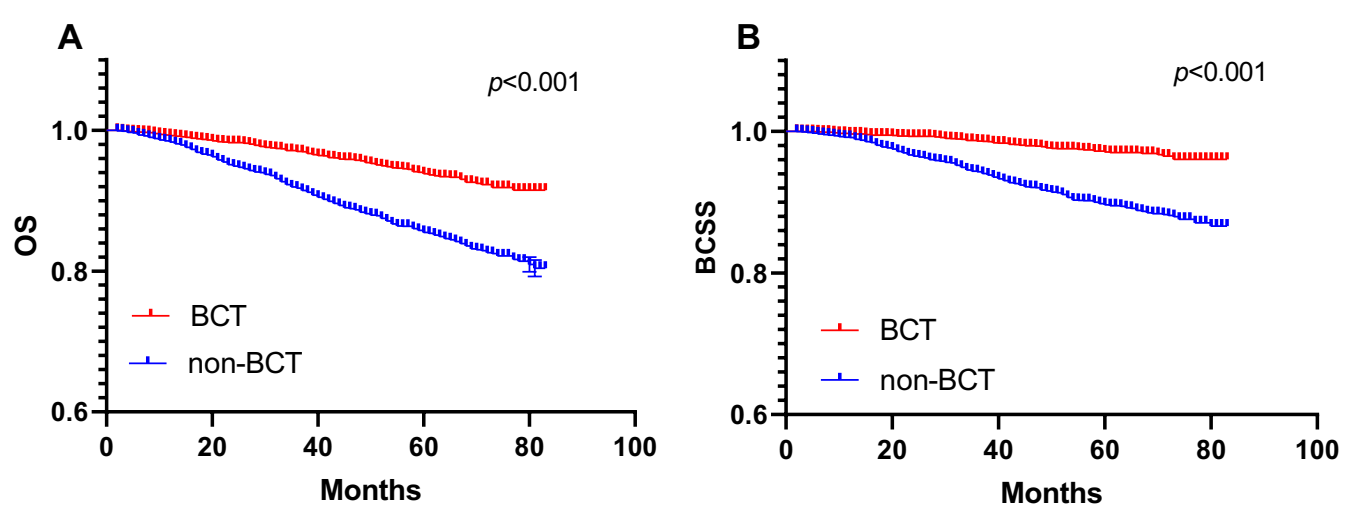

Fig. 2 Kaplan-Meier survival curves of overall survival and breast cancer-specific survival stratified by BCT and non-BCT (A: OS; B: BCSS)

be viewed as equivalent treatments in early stage breast cancer (ESBC) $[17,18]$. Breast conserving therapy followed by radiotherapy allows patients to achieve esthetic outcomes, quality of life and preserve their breast without sacrificing oncologic outcome [1-3] and is considered as a safe treatment for early-stage breast cancer.

The term subareolar defined differently: Fowble et al. [7] and Haffty et al. [6] defined it as the area within $2 \mathrm{~cm}$ of the NAC, Haagensen shrank the distance to only $1 \mathrm{~cm}$, and Simmons et al. [5] defined it as the area immediately beneath the areola. Central tumors usually refer to subareolar with some exceptions: only include NAC [19], tumors $>2 \mathrm{~cm}$ from areolar margin [7]. NAC malignant tumors included Paget disease, lymphoma and invasive and noninvasive breast cancers [20] and Paget disease were also a candidate for BCT [21]. In our study NAC account for $6.42 \%(559 / 8702)$ central and NAC patients, and the type of surgery did not correlated with location significantly $(p=0.692)$. But to date, the research on $B C T$ of the NAC breast cancer is limited, so NAC breast cancer were included for further study. The early studies on the safety of BCT for CLBC $[4,13-16]$ or the comparation of oncological outcomes between $\mathrm{BCT}$ and nonBCT $[7,8]$ and the recent SEER based result [12] were all constrained to T1-2 stage. So in our study, T3-4 patients were included. Wang's study compared the safety of BCT versus mastectomy for CLBC [22]. But in our study, nonbreast conserving patients included not only mastectomy, but also breast reconstruction.

Our result showed a trend of BCT for CLBC and it exceed non-BCT in 2015, and the proportion of BCT was similar to whole breast cancer reported in French (57\%) and English (63\%) [23]. We found a higher proportion of older age, single marital status, later years at diagnosis, lower grade, lower $\mathrm{T}$ stage, lower $\mathrm{N}$ stage, ER positive status, PR positive status and HER-2 negative status to receive $\mathrm{BCT}$ for CLBC and those factors were thought to be associated with favored outcome.

The young breast cancer always develops more aggressive tumors at diagnosis, like hormone receptor negative, higher grade, and HER-2 negative [24] and it is not contraindication for BCT for early stage patients. In our logistic analysis, we found that there is a significantly lower proportion of a young age ( $<45$ yeasts old $)$ in BCT group $(6.40 \%)$ compared with non-BCT group $(14.8 \%)$. With the popularization of BRCA1/2 genetic testing and the maturity of breast reconstruction surgery, more and more young women are choosing breast reconstruction and contralateral prophylactic mastectomy $[25,26]$. This may be why more young women are not opting for breast conserving surgery.

The evidence for breast conserving surgery has expanded with the availability of more drugs and improved efficacy of neoadjuvant therapy. Breast conserving surgery is not limited to early stage, such as $\mathrm{T} 1-\mathrm{T} 2$, but can be extended to T3-4. In our research, the OS rate of central breast cancer patents was higher with breast conserving surgery than with mastectomy, which was consistent with Zhang's results [12]. However, our study demonstrates that T3-T4 and stage III patients receiving breast conserving therapy also had higher OS $(\mathrm{P}<0.05)$.

And BCT significantly reduced overall death hazard (HR 0.633; 95\%CT 0.522-0.766; $\mathrm{P}<0.001)$ and 
Table 3 Univariable and multivariable models of overall mortality in central breast cancer patients

\begin{tabular}{|c|c|c|c|c|}
\hline & \multicolumn{2}{|l|}{ Univariate analysis } & \multicolumn{2}{|l|}{ Multivariate analysis } \\
\hline & $\mathrm{HR}(95 \% \mathrm{Cl})$ & $P$-value & $\mathrm{HR}(95 \% \mathrm{Cl})$ & $P$-value \\
\hline Surgery type & & $<0.001$ & & $<0.001$ \\
\hline Non-BCT & Reference & & & \\
\hline $\mathrm{BCT}$ & $0.396(0.332-0.473)$ & $<0.001$ & $0.633(0.522-0.766)$ & $<0.001$ \\
\hline Age & & $<0.001$ & & $<0.001$ \\
\hline$<45$ & Reference & & Reference & \\
\hline $45-59$ & 1.029 (0.769-1.378) & 0.846 & $1.188(0.885-1.595)$ & 0.252 \\
\hline $60-79$ & $1.581(1.201-2.080)$ & 0.001 & $2.012(1.518-2.668)$ & $<0.001$ \\
\hline Race & & $<0.001$ & & $<0.001$ \\
\hline White & Reference & & Reference & \\
\hline Black & $1.922(1.568-2.356)$ & $<0.001$ & $1.509(1.222-1.864)$ & $<0.001$ \\
\hline Others & $0.630(0.466-0.851)$ & 0.003 & $0.566(0.418-0.767)$ & $<0.001$ \\
\hline Marital & & $<0.001$ & & $<0.001$ \\
\hline Married & Reference & & Reference & \\
\hline Single & $1.596(1.301-1.959)$ & $<0.001$ & $1.366(1.106-1.686)$ & 0.004 \\
\hline Divorced & $1.829(1.544-2.166)$ & $<0.001$ & $1.465(1.231-1.742)$ & $<0.001$ \\
\hline Year of diagnosis & $0.929(0.877-0.984)$ & 0.012 & $0.941(0.888-0.997)$ & 0.038 \\
\hline Grade & & $<0.001$ & & $<0.001$ \\
\hline Grade I & Reference & & Reference & \\
\hline Grade II & $1.392(1.081-1.793)$ & 0.01 & $1.025(0.792-1.326)$ & 0.85 \\
\hline Grade III & $3.189(2.497-4.071)$ & $<0.001$ & $1.581(1.211-2.065)$ & 0.001 \\
\hline Grade IV & $4.950(2.004-12.224)$ & 0.001 & $2.438(0.977-6.08)$ & 0.056 \\
\hline Tstage & & $<0.001$ & & $<0.001$ \\
\hline $\mathrm{T} 1$ & Reference & & Reference & \\
\hline $\mathrm{T} 2$ & $2.288(1.906-2.747)$ & $<0.001$ & $1.48(1.214-1.805)$ & $<0.001$ \\
\hline T3 & $4.055(3.208-5.126)$ & $<0.001$ & $1.947(1.498-2.529)$ & $<0.001$ \\
\hline T4 & $6.933(5.452-8.817)$ & $<0.001$ & $2.845(2.169-3.731)$ & $<0.001$ \\
\hline N stage & & $<0.001$ & & $<0.001$ \\
\hline NO & Reference & & Reference & \\
\hline N1 & $1.83(1.525-2.195)$ & $<0.001$ & $1.461(1.205-1.772)$ & $<0.001$ \\
\hline $\mathrm{N} 2$ & $3.999(3.214-4.976)$ & $<0.001$ & $2.482(1.956-3.149)$ & $<0.001$ \\
\hline N3 & $6.087(4.802-7.716)$ & $<0.001$ & $3.180(2.443-4.140)$ & $<0.001$ \\
\hline ER status & & $<0.001$ & & 0.003 \\
\hline Negative & Reference & & Reference & \\
\hline Positive & $0.362(0.307-0.427)$ & $<0.001$ & $0.692(0.544-0.880)$ & 0.003 \\
\hline PR status & & $<0.001$ & & $<0.001$ \\
\hline Negative & Reference & & Reference & \\
\hline Positive & $0.407(0.350-0.475)$ & $<0.001$ & $0.666(0.536-0.828)$ & $<0.001$ \\
\hline HER-2 status & & 0.004 & & 0.039 \\
\hline Negative & Reference & & Reference & \\
\hline Positive & $1.318(1.094-1.588)$ & 0.004 & $0.813(0.668-0.989)$ & 0.039 \\
\hline
\end{tabular}


Table 4 Univariable and multivariable models of breast cancer-specific mortality in central breast cancer patients

\begin{tabular}{|c|c|c|c|c|}
\hline & \multicolumn{2}{|l|}{ Univariate analysis } & \multicolumn{2}{|l|}{ Multivariate analysis } \\
\hline & HR $(95 \% C l)$ & P-value & $\mathrm{HR}(95 \% \mathrm{Cl})$ & P-value \\
\hline Surgery type & & $<0.001$ & & $<0.001$ \\
\hline Non-BCT & Reference & & Reference & \\
\hline $\mathrm{BCT}$ & $0.266(0.206-0.342)$ & $<0.001$ & $0.570(0.435-0.746)$ & $<0.001$ \\
\hline Age & & $<0.001$ & & 0.894 \\
\hline$<45$ & Reference & & Reference & \\
\hline $45-59$ & $1.131(0.843-1.518)$ & 0.411 & $1.075(0.79-1.463)$ & 0.645 \\
\hline $60-79$ & $1.904(1.437-2.524)$ & $<0.001$ & $1.069(0.785-1.455)$ & 0.672 \\
\hline Race & & $<0.001$ & & $<0.001$ \\
\hline White & Reference & & Reference & \\
\hline Black & $1.505(1.218-1.859)$ & $<0.001$ & $1.473(1.137-1.91)$ & 0.003 \\
\hline Others & $0.581(0.429-0.787)$ & $<0.001$ & $0.549(0.374-0.806)$ & 0.002 \\
\hline Marital & & $<0.001$ & & 0.007 \\
\hline Married & Reference & & Reference & \\
\hline Single & $1.355(1.097-1.672)$ & 0.005 & $1.244(0.957-1.618)$ & 0.103 \\
\hline Divorced & $1.478(1.243-1.758)$ & $<0.001$ & $1.43(1.141-1.792)$ & 0.002 \\
\hline Year of diagnosis & $0.935(0.882-0.99)$ & 0.022 & $0.949(0.881-1.022)$ & 0.167 \\
\hline Grade & & $<0.001$ & & $<0.001$ \\
\hline Grade I & Reference & & Reference & \\
\hline Grade II & $1.04(0.804-1.346)$ & 0.763 & $1.763(1.109-2.803)$ & 0.017 \\
\hline Grade III & $1.612(1.233-2.106)$ & 0 & 3.159 (1.984-5.029) & $<0.001$ \\
\hline Grade IV & $2.439(0.977-6.091)$ & 0.056 & $4.019(1.179-13.706)$ & 0.026 \\
\hline Tstage & & $<0.001$ & & $<0.001$ \\
\hline $\mathrm{T} 1$ & Reference & & Reference & \\
\hline $\mathrm{T} 2$ & $1.616(1.329-1.966)$ & $<0.001$ & $1.913(1.441-2.54)$ & $<0.001$ \\
\hline T3 & $2.241(1.733-2.897)$ & $<0.001$ & $2.798(1.998-3.919)$ & $<0.001$ \\
\hline T4 & $3.251(2.487-4.25)$ & $<0.001$ & $4.072(2.868-5.782)$ & $<0.001$ \\
\hline N stage & & $<0.001$ & & $<0.001$ \\
\hline No & Reference & & Reference & \\
\hline N1 & $1.532(1.264-1.857)$ & $<0.001$ & $1.907(1.465-2.483)$ & $<0.001$ \\
\hline N2 & $2.725(2.151-3.452)$ & $<0.001$ & $3.525(2.599-4.781)$ & $<0.001$ \\
\hline N3 & $3.518(2.706-4.573)$ & $<0.001$ & $4.546(3.282-6.297)$ & $<0.001$ \\
\hline ER status & & 0.003 & & 0.005 \\
\hline Negative & Reference & & & \\
\hline Positive & $0.695(0.546-0.885)$ & 0.003 & Reference & 0.005 \\
\hline PR status & & $<0.001$ & & $<0.001$ \\
\hline Negative & Reference & & Reference & \\
\hline Positive & $0.664(0.534-0.825)$ & $<0.001$ & $0.519(0.395-0.681)$ & $<0.001$ \\
\hline HER-2 status & & 0.045 & & 0.008 \\
\hline Negative & Reference & & Reference & \\
\hline Positive & $0.818(0.672-0.995)$ & 0.045 & $0.723(0.569-0.918)$ & 0.008 \\
\hline
\end{tabular}


Table 5 Comparisons of clinicopathological characteristics between the BCT and non-BCT group in 1:1 matched casecontrol analysis

\begin{tabular}{|c|c|c|c|c|c|}
\hline & \multicolumn{2}{|c|}{ Non-BCT } & \multicolumn{2}{|l|}{$\mathrm{BCT}$} & \multirow[t]{2}{*}{$P$-value } \\
\hline & No & $\%$ & No & $\%$ & \\
\hline Year of diagnosis & & & & & $<0.001$ \\
\hline 2010 & 478 & 17.30 & 420 & 15.20 & \\
\hline 2011 & 420 & 15.20 & 426 & 15.50 & \\
\hline 2012 & 500 & 18.10 & 436 & 15.80 & \\
\hline 2013 & 480 & 17.40 & 437 & 15.90 & \\
\hline 2014 & 442 & 16.00 & 483 & 17.50 & \\
\hline 2015 & 437 & 15.90 & 555 & 20.10 & \\
\hline Age & & & & & 0.114 \\
\hline$<45$ & 233 & 8.50 & 244 & 8.90 & \\
\hline $45-59$ & 1035 & 37.50 & 1101 & 39.90 & \\
\hline 60-79 & 1489 & 54.00 & 1412 & 51.20 & \\
\hline Race & & & & & 0.527 \\
\hline White & 2202 & 79.90 & 2169 & 78.70 & \\
\hline Black & 254 & 9.20 & 274 & 9.90 & \\
\hline Others & 301 & 10.90 & 314 & 11.40 & \\
\hline Marital & & & & & 0.287 \\
\hline Married & 1713 & 62.10 & 1671 & 60.60 & \\
\hline Single & 405 & 14.70 & 446 & 16.20 & \\
\hline Divorced & 639 & 23.20 & 640 & 23.20 & \\
\hline Grade & & & & & 0.669 \\
\hline Grade I & 585 & 21.20 & 569 & 20.60 & \\
\hline Grade II & 1360 & 49.30 & 1406 & 51.00 & \\
\hline Grade III & 805 & 29.20 & 775 & 28.10 & \\
\hline Grade IV & 7 & 0.30 & 7 & 0.30 & \\
\hline T stage & & & & & 0.722 \\
\hline $\mathrm{T} 1$ & 1692 & 61.40 & 1676 & 60.80 & \\
\hline $\mathrm{T} 2$ & 918 & 33.30 & 948 & 34.40 & \\
\hline T3 & 85 & 3.10 & 79 & 2.90 & \\
\hline $\mathrm{T} 4$ & 62 & 2.20 & 54 & 2.00 & \\
\hline N stage & & & & & 0.547 \\
\hline No & 1760 & 63.80 & 1799 & 65.30 & \\
\hline N1 & 843 & 30.60 & 815 & 29.60 & \\
\hline N2 & 108 & 3.90 & 107 & 3.90 & \\
\hline N3 & 46 & 1.70 & 36 & 1.30 & \\
\hline ER status & & & & & 0.579 \\
\hline Negative & 375 & 13.60 & 360 & 13.10 & \\
\hline Positive & 2382 & 86.40 & 2397 & 86.90 & \\
\hline PR status & & & & & 0.409 \\
\hline Negative & 636 & 23.10 & 662 & 24.00 & \\
\hline Positive & 2121 & 76.90 & 2095 & 76.00 & \\
\hline HER-2 status & & & & & 0.458 \\
\hline Negative & 2316 & 84.00 & 2337 & 84.80 & \\
\hline Positive & 441 & 16.00 & 420 & 15.20 & \\
\hline
\end{tabular}

breast-specific death hazard (HR 0.570; 95\%CT $0.435-$ 0.746; $\mathrm{P}<0.001)$ in the adjust multivariate Cox analysis. When dug deeply, we found that there is a higher proportion of older age, single marital status, more recent years at diagnosis, lower grade, lower $\mathrm{T}$ stage, lower $\mathrm{N}$ stage, ER positive status, PR positive status and HER-2 negative status to receive BCT for CLBC and those factors were thought to be associated with favored survival outcome. To eliminate the effect of those confounders on prognosis analysis, propensity match score was used. Post-match cohort showed an improved survival in $\mathrm{BCT}$ compared with non-BCT in central and NAC tumors.

One limitation of breast conserving surgery for central breast cancer is postoperative aesthetics. In cases of tumor involvement of the nipple-areola complex, the surgeon may remove the nipple-areola complex to ensure a negative margin. This will bring great damage to postoperative breast aesthetics. Overall, nipple areola composite reconstruction will improve patient satisfaction and confidence. With the development of plastic surgery, a variety of methods of nipple areola composite reconstruction can be achieved, including tattooing, using synthetic materials, local flaps, and grafts [27-30]. This will make up for the shortcomings of breast conserving surgery in central breast cancer. Priya et al. demonstrated for patients with central tumor treated with neoadjuvant chemotherapy, many patients may have successfully converted to nipple-areola complex after reevaluation at the end of chemotherapy [31].

On the premise that the tumor safety and aesthetics can be achieved, breast conserving surgery for central breast cancer is a desirable option.

We recognize several limitations of this study. First of all, this study is a retrospective study with inherent flaws. Even though we use the PSM method, there will still be some biases. Secondly, because the patient's BRCA gene information is not available, it is impossible to evaluate its impact on the breast cancer surgery in the central region. Third, there is no information about postoperative complications, satisfaction and cosmetic results of breast conserving surgery in our study. Finally, the SEER database does not collect socioeconomic and baseline health information, which may be the relationship between surgical methods and survival. In the absence of prospective high-level evidence, our current large-sample retrospective study is of great significance to assess tumor safety, and more prospective studies are needed in the future. 

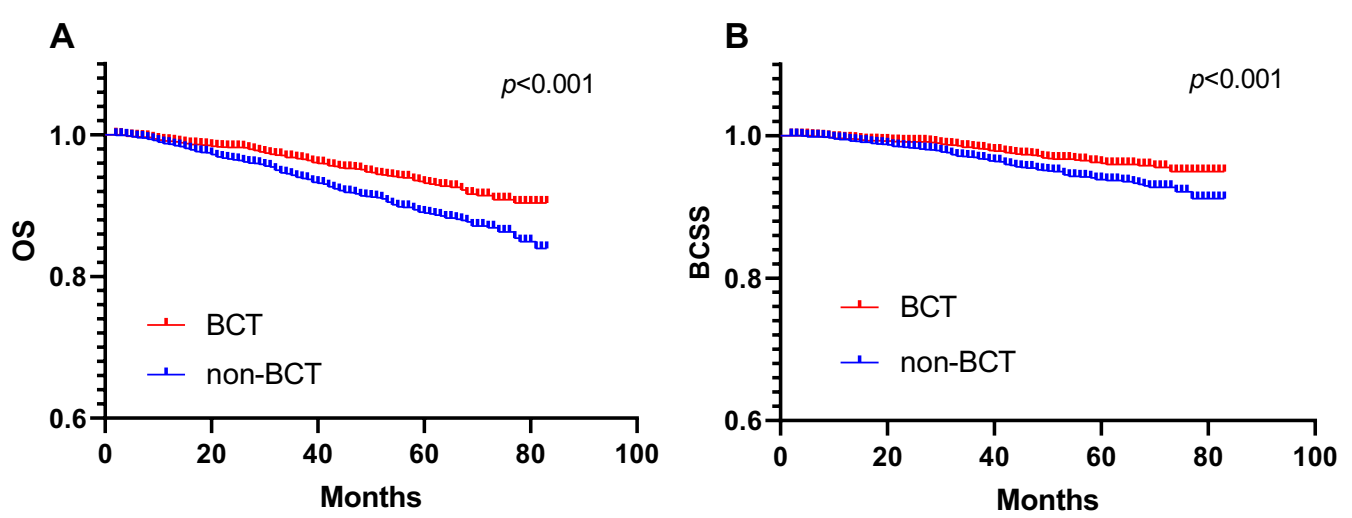

Fig. 3 Kaplan-Meier survival curves of overall survival and breast cancer-specific survival stratified by BCT and non-BCT in matched case-control analysis (A: OS; $\mathbf{B}:$ BCSS)
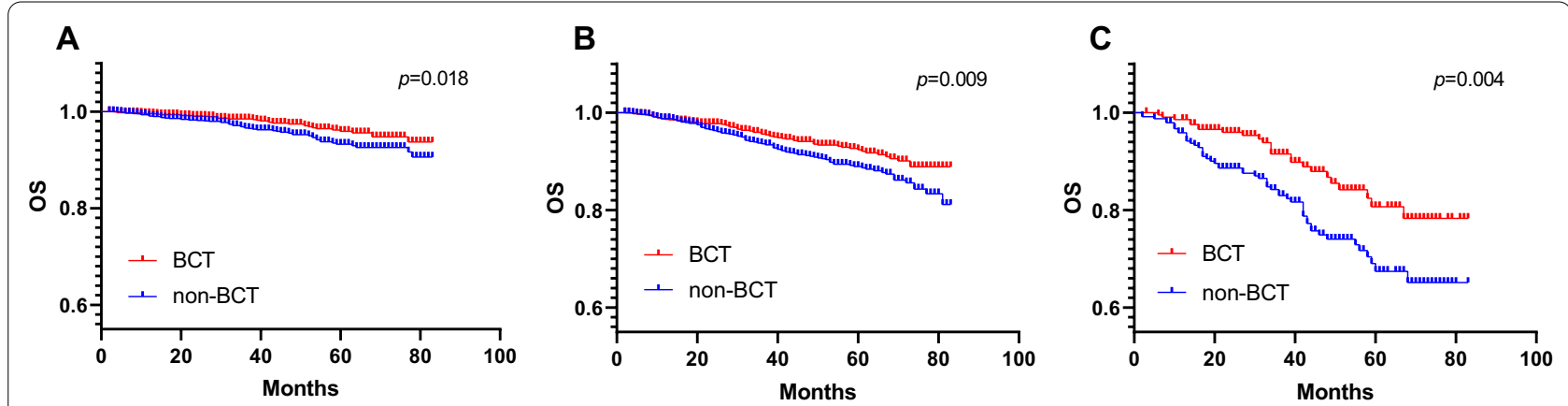

Fig. 4 Kaplan-Meier survival curves of overall survival for BCT and non-BCT stratified by the stage in matched case-control analysis (A stage l; B stage II; C stage III)
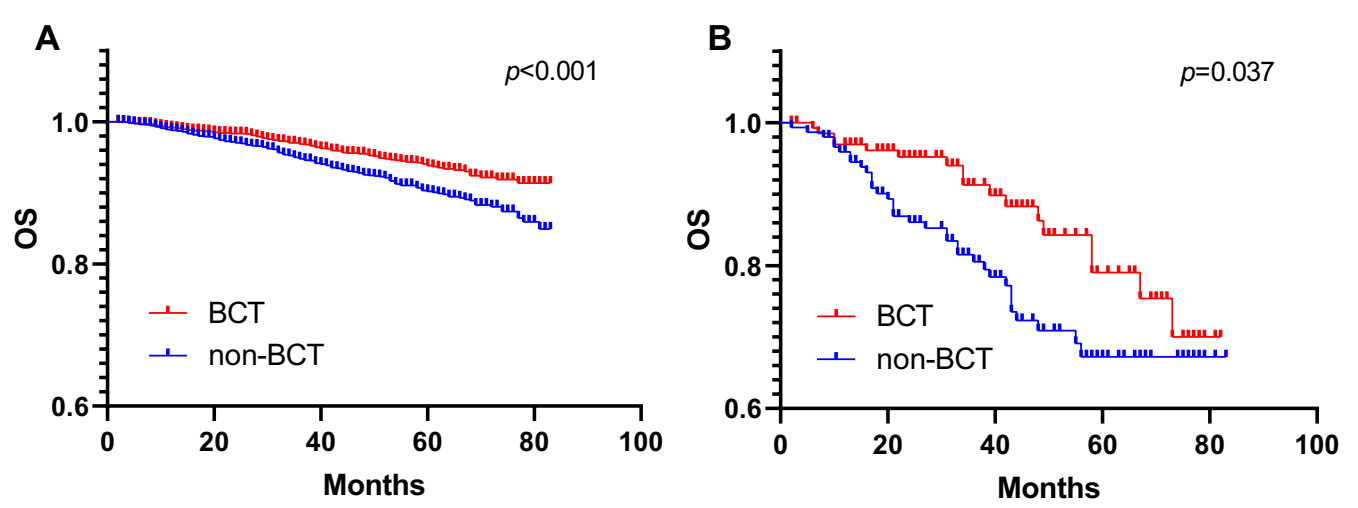

Fig. 5 Kaplan-Meier survival curves of overall survival for BCT and non-BCT stratified by the T stage in matched case-control analysis (A:T1-2; B: T3-4) 


\section{Conclusion}

There is an increased incidence of BCT in patients with central breast cancer. Old age and low tumor malignancy were predictors of BCT. BCT is a safe and feasible surgical procedure for central breast cancer.

\section{Acknowledgements}

We are grateful for the registration of SEER program for the creation of the SEER database.

\section{Authors' contributions}

Conception and design: $J$ and $X Z$; Development of methodology: $J, X Z, H H$, SL and CX; Acquisition of data, analysis and interpretation of data (e.g., statistical analysis, biostatistics, computational analysis): JL, XZ, CX; Writing, review and/or revision of the manuscript: JL, XZ and CX; Study supervision: JL and SL; Revising: JL, XZ and CX; All of the authors reviewed, read and approved the final manuscript.

\section{Funding}

Not applicable.

\section{Availability of data and materials}

These data were publicly available for use in accordance with a limited use agreement for SEER research data: Surveillance, Epidemiology, and End Results (SEER) Program (https://seer.cancer.gov) SEER*Stat Database.

\section{Declarations}

\section{Ethics approval and consent to participate}

The study was conducted in accordance with the Declaration of Helsinki (as revised in 2013). We have obtained permission to access research data files in the SEER program of the National Cancer Institute (reference number 10727 Nov2020). The analysis dataset was extracted without any identifiable information. Thus, informed consent has been waived. Ethical approval was exempt from review by the Ethics Committee of Fujian Medical University Union Hospital, as SEER database is publicly available and without specific identifiers.

\section{Consent for publication}

Not applicable.

\section{Competing interests}

The authors declare that they have no competing interests.

\section{Author details}

${ }^{1}$ The Graduate School of Fujian Medical University, Fuzhou 350000, Fujian, China. ${ }^{2}$ Department of Breast Surgery, Fujian Medical University Union Hospital, No. 29, Xinquan Road, Fuzhou 350001, Fujian, China. ${ }^{3}$ Department of General Surgery, Fujian Medical University Union Hospital, Fuzhou 350001, Fujian, China. ${ }^{4}$ Breast Cancer Institute, Fujian Medical University, Fuzhou 350001 Fujian, China. ${ }^{5}$ Department of Radiotherapy, Fujian Medical University Cancer Hospital, Fuzhou 350000, Fujian, China.

Received: 21 September 2021 Accepted: 20 January 2022

Published online: 29 January 2022

\section{References}

1. Blichert-Toft M, Nielsen M, Düring M, Møller S, Rank F, Overgaard M, Mouridsen HT. Long-term results of breast conserving surgery vs mastectomy for early stage invasive breast cancer: 20-year follow-up of the Danish randomized DBCG-82TM protocol. Acta Oncol. 2008;47(4):672-81.

2. Litière $S$, Werutsky $G$, Fentiman IS, Rutgers E, Christiaens M-R, Van Limbergen E, Baaijens MHA, Bogaerts J, Bartelink H. Breast conserving therapy versus mastectomy for stage I-II breast cancer: 20 year follow-up of the EORTC 10801 phase 3 randomised trial. Lancet Oncol. 2012;13(4):412-9.

3. Curran D, van Dongen JP, Aaronson NK, Kiebert G, Fentiman IS, Mignolet F, Bartelink H. Quality of life of early-stage breast cancer patients treated with radical mastectomy or breast-conserving procedures: results of EORTC Trial 10801. The European Organization for Research and Treatment of Cancer (EORTC), Breast Cancer Co-operative Group (BCCG). Eur J Cancer (Oxford, England: 1990). 1998;34(3):307-14.

4. Pezzi CM, Kukora JS, Audet IM, Herbert SH, Horvick D, Richter MP. Breast conservation surgery using nipple-areolar resection for central breast cancers. Arch Surg. 2004;139(1):32-7.

5. Simmons RM, Brennan MB, Christos P, Sckolnick M, Osborne M. Recurrence rates in patients with central or retroareolar breast cancers treated with mastectomy or lumpectomy. Am J Surg. 2001;182(4):325-9.

6. Haffty BG, Wilson LD, Smith R, Fischer D, Beinfield M, Ward B, McKhann C. Subareolar breast-cancer-long-term results with conservative surgery and radiation-therapy. Int J Radiat Oncol Biol Phys. 1995;33(1):53-7.

7. Fowble B, Solin LJ, Schultz DJ, Weiss MC. Breast recurrence and survival related to primary tumor location in patients undergoing conservative surgery and radiation for early-stage breast-cancer. Int J Radiat Oncol Biol Phys. 1992;23(5):933-9.

8. Fitzal F, Mittlboeck M, Trischler H, Krois W, Nehrer G, Deutinger M, Jakesz $\mathrm{R}$, Gnant M. Breast-conserving therapy for centrally located breast cancer. Ann Surg. 2008;247(3):470-6.

9. Lagios MD, Gates EA, Westdahl PR, Richards V, Alpert BS. A guide to the frequency of nipple involvement in breast cancer. A study of 149 consecutive mastectomies using a serial subgross and correlated radiographic technique. Am J Surg. 1979;138(1):135-42.

10. Morimoto T, Komaki K, Inui K, Umemoto A, Yamamoto H, Harada K, Inoue K. Involvement of nipple and areola in early breast cancer. Cancer. 1985;55(10):2459-63.

11. Suehiro S, Inai K, Tokuoka S, Hamada Y, Toi M, Niimoto M, Hattori T. Involvement of the nipple in early carcinoma of the breast. Surg Gynecol Obstet. 1989;168(3):244-8.

12. Zhang M, Wu K, Zhang P, Wang M, Bai F, Chen H. Breast-conserving surgery is oncologically safe for well-selected, centrally located breast cancer. Ann Surg Oncol. 2020;28(1):330-9.

13. Dale PS, Giuliano AE. Nipple-areolar preservation during breastconserving therapy for subareolar breast carcinomas. Arch Surg. 1996;131(4):430-3.

14. Eggemann $\mathrm{H}$, Ignatov $A$, Elling $D$, Lampe $D$, Lantzsch $T$, Weise M, Costa SD. Efficacy and patient satisfaction of breast conserving therapy for central breast cancer by the B technique. Ann Surg Oncol. 2013;20(11):3438-45.

15. Bussieres E, Guyon F, Thomas L, Stockle E, Faucher A, Durand M. Conservation treatment in subareolar breast cancers. Eur J Surg Oncol. 1996;22(3):267-70.

16. Gajdos C, Tartter PI, Bleiweiss IJ. Subareolar breast cancers. Am J Surg. 2000;180(3):167-70.

17. Fisher B, Anderson S, Bryant J, Margolese RG, Deutsch M, Fisher ER, Jeong $\mathrm{J}-\mathrm{H}$, Wolmark N. Twenty-year follow-up of a randomized trial comparing total mastectomy, lumpectomy, and lumpectomy plus irradiation for the treatment of invasive breast cancer. N Engl J Med. 2002;347(16):1233-41.

18. Arriagada R, Lê MG, Rochard F, Contesso G. Conservative treatment versus mastectomy in early breast cancer: patterns of failure with 15 years of follow-up data. Institut Gustave-Roussy Breast Cancer Group. J Clin Oncol. 1996;14(5):1558-64.

19. Wu S, Zhou J, Ren Y, Sun J, Li F, Lin Q, Lin H, He Z. Tumor location is a prognostic factor for survival of Chinese women with T1-2N0M0 breast cancer. Int J Surg. 2014:12(5):394-8.

20. Streng A, Gutjahr E, Aulmann S, Flechtenmacher C, Toberer F, Heil J, Böcker W, Sinn P. Pathology of the nipple-areola complex. I. Paget's disease of the nipple, variants, and differential diagnoses. Pathologe. 2020:41(4):393-9.

21. Sakorafas GH, Blanchard K, Sarr MG, Farley DR. Paget's disease of the breast. Cancer Treat Rev. 2001. https://doi.org/10.1053/ctrv.2000.0203.

22. Wang J, Wang X, Zhong Z, Li X, Sun J, Li J, Huang J, Li Y, Ren G, Li H. Breast-conserving therapy has better prognosis for tumors in the central and nipple portion of breast cancer compared with mastectomy: a SEER data-based study. Front Oncol. 2021;11: 642571.

23. Sant M. Differences in stage and therapy for breast cancer across Europe. Int J Cancer. 2001;93(6):894-901.

24. Rosenberg SM, Partridge AH. Management of breast cancer in very young women. Breast. 2015;24(Suppl 2):S154-158.

25. Teoh V, Tasoulis MK, Gui G. Contralateral prophylactic mastectomy in women with unilateral breast cancer who are genetic carriers, have a 
strong family history or are just young at presentation. Cancers. 2020. https://doi.org/10.3390/cancers12010140.

26. Panchal H, Pilewskie ML, Sheckter CC, Albornoz CR, Razdan SN, Disa $\mathrm{JJ}$, Cordeiro PG, Mehrara BJ, Matros E. National trends in contralateral prophylactic mastectomy in women with locally advanced breast cancer. J Surg Oncol. 2019;119(1):79-87.

27. Jabor MA, Shayani P, Collins DR, Karas T, Cohen BE. Nipple-areola reconstruction: satisfaction and clinical determinants. Plast Reconstr Surg. 2002. https://doi.org/10.1097/00006534-200208000-00013.

28. Kristoffersen CM, Seland $H$, Hansson E. A systematic review of risks and benefits with nipple-areola-reconstruction. J Plast Surg Hand Surg. 2017;51(5):287-95.

29. Losken A, Mackay GJ, Bostwick J. Nipple reconstruction using the C-V flap technique: a long-term evaluation. Plast Reconstr Surg. 2001;108(2):361-9.

30. Spear SL, Convit R, Little JW. Intradermal tattoo as an adjunct to nippleareola reconstruction. Plast Reconstr Surg. 1989;83(5):907-11.

31. Jadeja P, Ha R, Rohde C, Ascherman J, Grant R, Chin C, Connolly E, Kalinsky K, Feldman S, Taback B. Expanding the criteria for nipple-sparing mastectomy in patients with poor prognostic features. Clin Breast Cancer. 2018;18(3):229-33.

\section{Publisher's Note}

Springer Nature remains neutral with regard to jurisdictional claims in published maps and institutional affiliations.

- fast, convenient online submission

- thorough peer review by experienced researchers in your field

- rapid publication on acceptance

- support for research data, including large and complex data types

- gold Open Access which fosters wider collaboration and increased citations

- maximum visibility for your research: over $100 \mathrm{M}$ website views per year

At BMC, research is always in progress.

Learn more biomedcentral.com/submissions 